\title{
O modelo de excelência da gestão (MEG) favorece a existência das organizações do conhecimento de Chun W. Choo? ${ }^{1}$
}

\author{
The excellence management model foments the existence of the knowledge organizations of \\ Chun W. Choo?
}

\begin{abstract}
Leonardo Guimarães Garcia
Doutor em Ciência e Engenharia dos Materiais pela Universidade Federal de São Carlos - UFSCAR. Docente do curso de Biblioteconomia, Ciências da Informação e da Documentação da Faculdade de Filosofia, Ciências e Letras de Ribeirão Preto da Universidade de São Paulo - FFCLRP/USP.

E-mail: leonardogarcia@ffclrp.usp.br
\end{abstract}

\section{Resumo}

O presente artigo discute se o fato de uma organização utilizar plenamente o Modelo de Excelência da Gestão (MEG) favorece sua transformação no que Choo (2006) denomina "Organização do Conhecimento". Para tanto, realizou-se um levantamento bibliográfico do qual se extraiu os elementos essenciais do MEG e das organizações do conhecimento de Choo, permitindo assim a comparação entre os modelos. Desse confronto, conclui-se que, em tese, o MEG favorece a existência das organizações do conhecimento, mas que a exploração efetiva dos benefícios oferecidos pelo MEG carece da intervenção de profissionais da informação, por meio de uma gestão da informação que compatibilize as demandas organizacionais às especificidades do modelo de Choo.

Palavras-chave: Chun Wei Choo. Modelo de Excelência da Gestão. Criação de Significado. Construção de Conhecimento. Tomada de Decisões.

\begin{abstract}
This article discusses if the full utilization of the Excellence Management Model (EMG) favors an organizational transformation towards what Choo (2006) calls "Knowledge Organization". Therefore, a bibliographic review was carried out and the essential elements of EMG and Choo's knowledge organizations were determined, allowing a comparison between these models. Through this confrontation, it is concluded that, in thesis, EMG foments the existence of knowledge organizations, but the effective exploitation of the benefits offered by EMG requires the information professionals intervention through an information management that reconciles the organization demands with the specificities of Choo's model.
\end{abstract}

Keywords: Chun Wei Choo. The Excellence Management Model. Sense Making. Knowledge Construction. Decision Making.

${ }^{1}$ Trabalho parcialmente apresentado no XV Encontro Nacional de Pesquisa em Ciência da Informação ENANCIB 2014

InCID: R. Ci. Inf. e Doc., Ribeirão Preto, v. 7, n. 1, p. 66-89, mar./ago. 2016.

DOI: 10.11606/issn.2178-2075.v7i1p66-89 


\section{Introdução}

Com o mundo em constante transformação, as organizações precisam enfrentar o desafio de compreender o contexto em que se inserem para, então, se posicionarem proativamente frente às necessidades sociais que se propõem a satisfazer.

Tal compreensão, por sua vez, exige o domínio dos fluxos informacionais internos e externos, bem como a conversão de suas informações em conhecimento, inovações e decisões, todos alinhados aos objetivos da organização.

Essa visão dos processos informacionais é a marca da "Organização do Conhecimento" de Chun Wei Choo: um modelo de criação de significado, construção de conhecimento e tomada de decisão, cuja profundidade e abrangência o tornam referência para organizações que alavancam seu sucesso por meio de informações e conhecimento.

No entanto, o reconhecimento generalizado desses fatores levou à criação de outras referências com o mesmo propósito. Uma delas está contida no Modelo de Excelência da Gestão (MEG). Sob a responsabilidade da Fundação Nacional da Qualidade (FNQ http://www.fnq.org.br/), o MEG é um modelo gerencial de referência, sistêmico e evolutivo, concebido para ser um guia na busca da gestão de excelência.

Por tratar as informações e o conhecimento como elementos indispensáveis ao sucesso organizacional, o MEG comunga do mesmo propósito do modelo de Choo. Além disso, a natureza não-prescritiva do MEG quanto às práticas e processos abre a possibilidade de coexistência entre os modelos, ou até mesmo do MEG facilitar o surgimento das organizações do conhecimento de Choo. Se assim o fosse, abrir-se-ia uma janela de oportunidades para a introdução das ideias de Choo em muitas organizações brasileiras que já utilizam o MEG, com a consequente melhoria do seu desempenho informacional.

Sendo assim, o presente artigo tem como objetivo investigar se o fato de uma organização utilizar plenamente o Modelo de Excelência da Gestão (MEG) favorece sua transformação no que Choo (2006) denomina “Organização do Conhecimento". 
O modelo de excelência da gestão (MEG) favorece a existência das organizações do conhecimento de Chun W. Choo?

\section{Método}

\subsection{Escolha do Corpus}

Tendo em vista o objetivo do artigo, realizou-se um levantamento bibliográfico sobre o MEG e o modelo de Choo nas seguntes fontes: a) base de periódicos CAPES; b) base Scielo; c) base BRAPCI; d) periódicos nacionais de Administração e Ciência da Informação, classificados nos estratos Qualis de A1 a B2; e) site institucional da FNQ.

A diversidade de ramificações revelada pelos trabalhos recuperados deixou claro que, para uma comparação efetiva dos modelos, seria necessário focar nos elementos primordiais de cada um. Dessa forma, foram selecionados apenas trabalhos estruturantes: aqueles necessários e suficientes à caracterização dos elementos essenciais do MEG e da organização do conhecimento de Choo. São eles: a) os dez cadernos da série "Cadernos de Excelência" (FUNDAÇÃO NACIONAL DA QUALIDADE, 2011a; 2011b; 2011c; 2011d; 2011e; 2011f; 2011g; 2011h; 2011i; 2011j); b) a obra FNQ (2013), por condensar as atualizações dos “Cadernos de Excelência” publicadas após 2011; c) o livro de Choo (2006) que descreve em detalhes as organizações do conhecimento ${ }^{2}$.

\subsection{Análise do Corpus}

A partir do corpus selecionado, a análise buscou responder à pergunta "O MEG favorece a existência das organizações do conhecimento?" por meio das seguintes atividades:

- Descrição dos aspectos essenciais do MEG (seção 3 do artigo). Com isso, estabeleceuse a referência do que seria uma organização que implanta o MEG em sua plenitude;

- Descrição do modelo de Choo (seção 4), explicitando as condições necessárias e suficientes, segundo o autor, para a existência da organização do conhecimento;

- Confronto entre os modelos com foco na pergunta supracitada (seção 5).

\footnotetext{
${ }^{2}$ Algumas obras complementares são citadas ao longo do artigo, apenas com o intuito de adensar o debate e acrescentar informações relevantes à caracterização extraída dos trabalhos estruturantes.
} 
Em resposta à demanda das organizações brasileiras por um modelo gerencial focado na busca da excelência, a Fundação Nacional da Qualidade (FNQ) desenvolveu o Modelo de Excelência da Gestão (MEG). Aplicável a organizações que qualquer tipo ou porte, o MEG é um modelo de referência, da categoria dos modelos "padronizados e genéricos, que desempenham um papel de referência para os agentes que tomam decisão a respeito de práticas a serem empregadas nas operações e nos processos organizacionais" (PAGLIUSO; CARDOSO; SPIEGEL, 2010).

A grande aceitação do MEG, não só entre as organizações privadas mas também entre as públicas (FERREIRA, 2012) deve-se, em grande parte, ao fato do modelo não se basear na prescrição de práticas ou ferramentas específicas, mas sim em princípios gerenciais adotados em todo o mundo por organizações de excelência reconhecida (FUNDAÇÃO NACIONAL DA QUALIDADE, 2011a). No caso do MEG, esses princípios são denominados "fundamentos da excelência” (vide Quadro 1).

QUADRO 1 - Fundamentos da excelência

\begin{tabular}{|c|l|}
\hline $\begin{array}{c}\text { Fundamentos da } \\
\text { Excelência }\end{array}$ & \multicolumn{1}{|c|}{ Definição } \\
\hline $\begin{array}{c}\text { Pensamento } \\
\text { sistêmico }\end{array}$ & $\begin{array}{l}\text { Compreensão e tratamento das relações de interdependência e seus efeitos entre os } \\
\text { diversos componentes da organização, bem como entre eles e o ambiente. }\end{array}$ \\
\hline Olhar para o futuro & $\begin{array}{l}\text { Projeção e compreensão de cenários e tendências prováveis do ambiente e dos possíveis } \\
\text { estratégias mais apropriadas. }\end{array}$ \\
\hline Inovação & $\begin{array}{l}\text { Promoção de um ambiente favorável à criatividade, experimentação e implementação de } \\
\text { novas ideias capazes de gerar ganhos de competitividade com desenvolvimento } \\
\text { sustentável. }\end{array}$ \\
\hline $\begin{array}{c}\text { Aprendizado } \\
\text { organizacional }\end{array}$ & $\begin{array}{l}\text { Busca de maior eficácia e eficiência dos processos da organização e alcance de um novo } \\
\text { patamar de competência, por meio da percepção, reflexão, avaliação e compartilhamento } \\
\text { de conhecimento e experiências. }\end{array}$ \\
\hline $\begin{array}{c}\text { Liderança } \\
\text { transformadora }\end{array}$ & $\begin{array}{l}\text { Atuação dos líderes de forma inspiradora, exemplar, realizadora e com constância de } \\
\text { propósito, estimulando as pessoas em torno de valores, princípios e objetivos da } \\
\text { organização, explorando as potencialidades das culturas presentes, preparando líderes e } \\
\text { interagindo com as partes interessadas. }\end{array}$ \\
\hline $\begin{array}{c}\text { Valorização das } \\
\text { pessoas e da } \\
\text { cultura }\end{array}$ & $\begin{array}{l}\text { Criação de condições favoráveis e seguras para as pessoas se desenvolverem } \\
\text { integralmente, com ênfase na maximização do desempenho, na diversidade e } \\
\text { fortalecimento de crenças, costumes e comportamentos favoráveis à excelência. }\end{array}$ \\
\hline $\begin{array}{c}\text { Orientação por } \\
\text { processos }\end{array}$ & $\begin{array}{l}\text { Busca de eficiência e eficácia nos conjuntos de atividades que formam a cadeia de } \\
\text { agregação de valor para os clientes e demais partes interessadas. }\end{array}$ \\
\hline $\begin{array}{c}\text { Conhecimento } \\
\text { sobre clientes e }\end{array}$ & $\begin{array}{l}\text { Interação com clientes e mercados e entendimento de suas necessidades, expectativas e } \\
\text { comportamentos, explícitos e potenciais, criando valor de forma sustentável. }\end{array}$ \\
\hline
\end{tabular}

InCID: R. Ci. Inf. e Doc., Ribeirão Preto, v. 7, n. 1, p. 66-89, mar./ago. 2016. 
O modelo de excelência da gestão (MEG) favorece a existência das organizações do conhecimento de Chun W. Choo?

\begin{tabular}{|c|l|}
\hline \multicolumn{1}{|c|}{ mercados } & \\
\hline Atuação em rede & $\begin{array}{l}\text { Desenvolvimento de relações e atividades em cooperação entre organizações ou } \\
\text { indivíduos com interesses comuns e competências complementares. }\end{array}$ \\
\hline $\begin{array}{c}\text { Responsabilidade } \\
\text { social }\end{array}$ & $\begin{array}{l}\text { Dever da organização de responder pelos impactos de suas atividades, na sociedade e no } \\
\text { meio ambiente, e de contribuir para a melhoria das condições de vida, por meio de um } \\
\text { comportamento ético e transparente, visando ao desenvolvimento sustentável. }\end{array}$ \\
\hline Geração de valor & $\begin{array}{l}\text { Alcance de resultados econômicos, sociais e ambientais, em níveis de excelência e que } \\
\text { atendam às necessidades das partes interessadas. }\end{array}$ \\
\hline Agilidade & $\begin{array}{l}\text { Flexibilidade e rapidez de adaptação a novas demandas das partes interessadas e } \\
\text { mudanças do ambiente, considerando a assimilação e o ciclo dos processos. }\end{array}$ \\
\hline $\begin{array}{c}\text { Decisões } \\
\text { fundamentadas }\end{array}$ & $\begin{array}{l}\text { Deliberações sobre direções a seguir e ações a executar, utilizando o conhecimento gerado } \\
\text { a partir do tratamento de informações obtidas em medições, avaliações e análises de } \\
\text { desempenho, de riscos, de retroalimentações e de experiências. }\end{array}$ \\
\hline
\end{tabular}

Fonte: FUNDAÇÃO NACIONAL DA QUALIDADE, 2013, p. 12.

O propósito do MEG é apresentar uma forma sistemática de compreensão e melhoria das práticas gerenciais. Para tanto, o modelo propõe oito critérios, compostos por diversos itens (Quadro 2). Os sete primeiros critérios são gerenciais, com itens que apontam que tipo de prática gerencial a organização necessita. Já os itens do critério "Resultados" servem para indicar os resultados organizacionais necessários ao modelo de gestão.

\section{QUADRO 2 - Critérios do MEG}

\begin{tabular}{|c|c|}
\hline Critérios & Escopo/Itens \\
\hline Liderança & $\begin{array}{l}\text { Trata das práticas gerenciais relacionadas à governança corporativa, ao exercício da } \\
\text { liderança, à promoção da excelência e à análise de desempenho }\end{array}$ \\
\hline $\begin{array}{l}\text { Estratégias e } \\
\quad \text { Planos }\end{array}$ & $\begin{array}{l}\text { Trata das práticas gerenciais relacionadas à formulação e implementação das estratégias } \\
\text { organizacionais }\end{array}$ \\
\hline Clientes & $\begin{array}{l}\text { Trata das práticas gerenciais relacionadas à imagem da organização, seu conhecimento } \\
\text { do mercado e seu relacionamento com os clientes }\end{array}$ \\
\hline Sociedade & $\begin{array}{l}\text { Trata das práticas gerenciais relacionadas à responsabilidade socioambiental e ao } \\
\text { desenvolvimento social }\end{array}$ \\
\hline $\begin{array}{l}\text { Informações e } \\
\text { Conhecimento }\end{array}$ & Trata das práticas gerenciais relacionadas à informação e ao conhecimento organizacional \\
\hline Pessoas & $\begin{array}{l}\text { Trata das práticas gerenciais relacionadas ao sistema de trabalho da organização, às } \\
\text { atividades de capacitação e desenvolvimento e à qualidade de vida }\end{array}$ \\
\hline Processos & $\begin{array}{l}\text { Trata das práticas gerenciais relacionadas aos processos organizacionais (principais, de } \\
\text { apoio, relativos aos fornecedores e econômico-financeiros) }\end{array}$ \\
\hline Resultados & $\begin{array}{l}\text { Trata dos resultados organizacionais nos âmbitos econômico-financeiro, de clientes e } \\
\text { mercado, da sociedade, das pessoas, dos processos e fornecedores }\end{array}$ \\
\hline
\end{tabular}

Fonte: FUNDAÇÃO NACIONAL DA QUALIDADE, 2011b; 2011c; 2011d; 2011e; 2011f; 2011g; 2011h; 2011i.

O Quadro 2 mostra que um dos critérios trata especificamente das informações e do conhecimento organizacional. Por meio dele, as organizações recebem orientações sobre o ciclo da informação, a identificação e a satisfação das necessidades informacionais dos colaboradores 
e sobre a gestão do conhecimento organizacional (FUNDAÇÃO NACIONAL DA QUALIDADE, 2011f; 2013).

Por se tratar de um modelo voltado à evolução, o MEG lança mão dos ciclos PDCA e PDCL para garantir a melhoria contínua: o ciclo PDCL leva à formalização de padrões de trabalho e introduz o aprendizado baseado na experiência; já o ciclo PDCA garante uma execução das práticas condizente com os padrões de trabalho. A consequencia é um impulso contínuo de ampliação da maturidade gerencial, desde o estágio inicial (denominado “Compromisso com a Excelência") até o mais avançado (chamado de "Excelência").

A averiguação dessa evolução baseia-se na avaliação das práticas gerenciais segundo as demandas dos critérios e seus itens. Para tanto, as organizações constituem avaliadores que utilizam perguntas padronizadas como o principal guia para a checagem. A análise das respostas baseia-se em fatores de avaliação, que representam princípios essenciais para a boa gestão, funcionando como uma bússula a excelência. O MEG possui quatro fatores de avaliação para os sete critérios gerenciais, e quatro outros, voltados ao critério "Resultados" (Quadro 3).

\begin{tabular}{|c|l|}
\multicolumn{2}{c|}{ QUADRO 3 - Fatores de avaliação do MEG } \\
\hline \multicolumn{2}{|c|}{ Fatores aplicáveis aos sete critérios gerenciais } \\
\hline Enfoque & $\begin{array}{l}\text { Avalia a pertinência das práticas frente ao item do critério MEG em questão, ao perfil } \\
\text { da organização e às particularidades importantes para a excelência. Avalia a } \\
\text { proatividade, a agilidade, a continuidade e o uso dos padrões pelas práticas. }\end{array}$ \\
\hline Aplicação & $\begin{array}{l}\text { Avalia quão difundidas são as práticas do item, se há um controle sobre o uso dos } \\
\text { padrões gerenciais e se as evidências requeridas estão presentes. }\end{array}$ \\
\hline Aprendizado & $\begin{array}{l}\text { Avalia se as práticas do item foram aperfeiçoadas com o tempo, se incorporaram } \\
\text { inovações e se são exemplares/referenciais para o seu setor de atuação. }\end{array}$ \\
\hline Integração & $\begin{array}{l}\text { Avalia a relação das práticas com os valores, princípios, estratégias e objetivos da } \\
\text { organização. Avalia ainda o quanto elas se interligam a outras práticas e o nível de } \\
\text { cooperação entre áreas e partes interessadas em seu projeto e implementação. }\end{array}$ \\
\hline \multicolumn{1}{|c|}{ Fatores aplicáveis ao critério "Resultados” } \\
\hline Relevância & $\begin{array}{l}\text { Avalia a suficiência dos resultados estratégicos e operacionais, apresentados por meio } \\
\text { de indicadores, frente às exigências do item. }\end{array}$ \\
\hline Competitividade & $\begin{array}{l}\text { Avalia se os resultados estratégicos e operacionais do item foram iguais ou superiores } \\
\text { aos referenciais comparativos eleitos para eles. }\end{array}$ \\
\hline Melhoria & Avalia se os resultados mostram melhoria ou estabilização em níveis aceitáveis. \\
\hline Compromisso & $\begin{array}{l}\text { Avalia se os resultados do item (ou sua melhoria) se igualam ou superam o esperado } \\
\text { pelas partes interessadas. }\end{array}$ \\
\hline
\end{tabular}

Fonte: FUNDAÇÃO NACIONAL DA QUALIDADE, 2013.

InCID: R. Ci. Inf. e Doc., Ribeirão Preto, v. 7, n. 1, p. 66-89, mar./ago. 2016. 


\section{As organizações do conhecimento de Chun Wei Choo}

Professor e pesquisador da Faculdade de Ciências da Informação da Universidade de Toronto, Chun Wei Choo publicou o livro "The Knowing Organization: how organizations use information to construct meaning, create knowledge, and make decisions", editado (2003) e reeditado (2006) no Brasil pela Editora SENAC.

Nessa obra, o autor apresenta os três usos estratégicos da informação que estabelecem as organizações do conhecimento, a saber: criação de significado, construção de conhecimento e tomada de decisões. Nessas organizações, "novas formas de conhecimento e de ação emergem quando as tensões entre o velho e o novo, entre mudança e estabilidade, são confrontadas, interpretadas e resolvidas" (CHOO, 2006, p. 381). Desse modo, cada um dos usos da informação desempenha uma função na manutenção da harmonia entre homeostase e adaptabilidade organizacional, equacionando contradições internas na busca do novo.

\subsection{Criação de Significado}

Esse uso estratégico da informação permite a geração de uma interpretação compartilhada do ambiente, orientando assim a ação dos membros da organização. Tal interpretação emerge da mobilização e do direcionamento, por meio da criação de significado, da tensão entre clareza e ambiguidade, e entre o consenso e a diversidade.

Choo (2006) indica o Sensemaking de Karl E. Weick como processo específico para efetivar a criação de significado, o qual é composto pelas seguintes etapas: a) Mudança ecológica, ou percepção pelos membros da organização de indícios de uma mudança ambiental relevante para as suas atividades; b) Interpretação, que corresponde à delimitação da mudança ambiental pela obtenção e tratamento de dados e informações pertinentes; c) Seleção, na qual dados e informações são analisados e discutidos coletivamente, para a escolha do significado capaz de explicar as mudanças ambientais percebidas; e d) Retenção, na qual se armazena o significado produzido para o uso da organização.

Para o seu pleno funcionamento, esse processo precisa promover a relação entre três recursos organizacionais: as crenças das pessoas (i.e., os filtros interpretativos do ambiente, compartilhados via cultura organizacional), suas representações tácitas dos aspectos mais determinantes do ambiente e suas interpretações formais dos acontecimentos ambientais. 
Para Choo, esses recursos são de três tipos (cognitivos, emocionais e ativos/situacionais, relacionados ao ambiente de uso da informação) e devem ser administrados por uma gestão da informação que apóie os ciclos de necessidade, busca e uso da informação (Figura 1). Na criação de significado, as crenças representam os recursos emocionais, as representações são os recursos ativos e as interpretações, os cognitivos.

Meio profissional/social (ambiente de uso da informação)

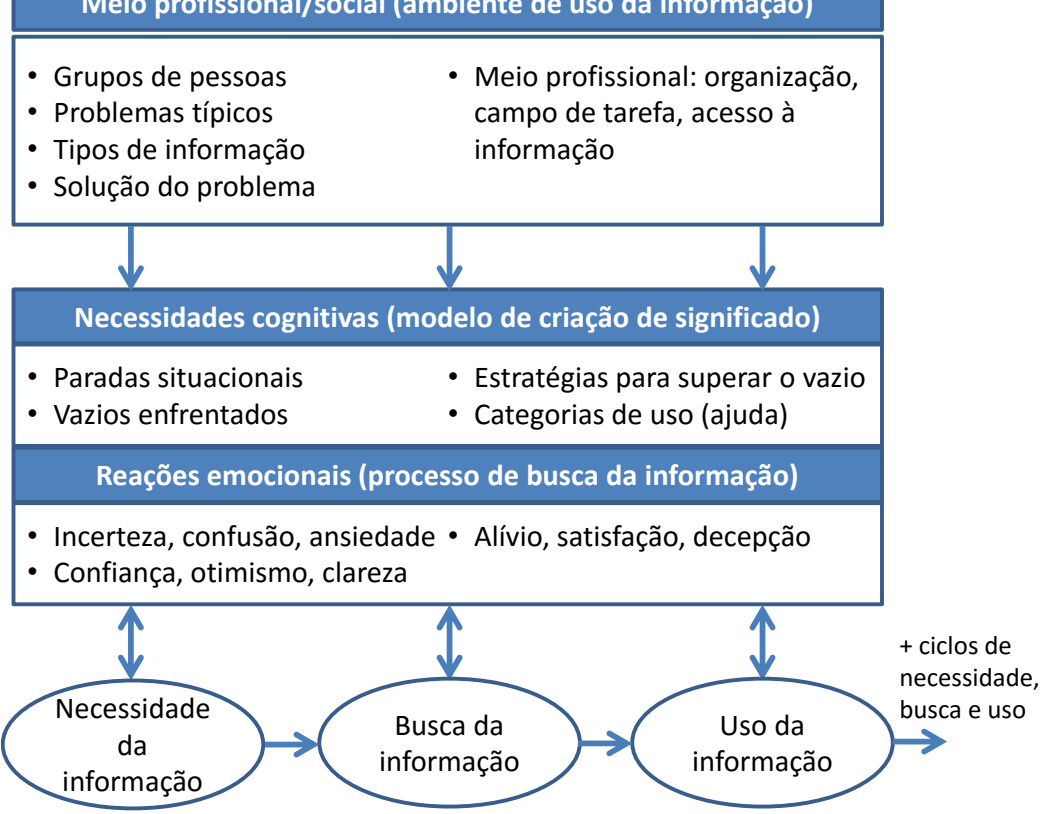

FIGURA 1 - Necessidades, busca e uso da informação nas organizações Fonte: Choo (2006, p. 114).

\subsection{Construção de Conhecimento}

Esse uso da informação culmina com a produção do conhecimento vital à competitidade, à melhoria e à geração de inovações. Para Choo, o conhecimento organizacional conjuga uma natureza explícita (i.e., cuja codificação não acarreta grandes perdas), tácita (representa o aspecto "não-codificável” do conhecimento, relacionado à experiência e à intuição dos indivíduos) e cultural (componente da cultura organizacional).

Segundo o autor, esses três recursos organizacionais (conhecimento tácito - do tipo ativo/situacional, explícito - do tipo cognitivo - e cultural - do tipo emocional) também formam, da mesma maneira que na criação de significado, uma relação de interdependência essencial para a efetivação desse uso estratégico da informação. A oposição entre o aspecto tácito e o explícito do conhecimento, bem como entre a exploração de conhecimentos estabelecidos e a investigação de novos, representa os pólos geradores de tensão entre o novo e o velho, cuja harmonização e direcionamento cabem à construção de conhecimento.

InCID: R. Ci. Inf. e Doc., Ribeirão Preto, v. 7, n. 1, p. 66-89, mar./ago. 2016. 
Choo (2006) apresenta algumas opções de processos específicos para a implementação desse uso estratégico da informação. Ele cita Nonaka e Takeuchi (1997), para os quais esse processo ocorre por meio da conversão do conhecimento tácito em explícito e vice-versa, por ações de socialização, exteriorização, combinação e internalização. Choo também cita a abordagem de Leonard-Barton, baseada em atividades criadoras de conhecimento (resolução compartilhada de problemas, experimentação/prototipagem, implementação de novas ferramentas e processos e importação de conhecimentos). Por fim, o autor discute a abordagem da conexão do conhecimento de Wikström e Normann, relacionada à transferência de conhecimento entre organizações parceiras por meio de suas interações.

\subsection{Tomada de Decisões}

Aqui, as informações são usadas de forma a garantir decisões adequadas, reduzindo o impacto das limitações da racionalidade humana por meio de premissas decisórias (ideias preconcebidas para nortear a tomada de decisão) e rotinas decisórias (procedimentos que guiam o comportamento decisório em situações predeterminadas). Aqui, a tensão criadora baseia-se na oposição entre ordem e improviso, e entre criação e evolução.

Choo (2006) cita um conjunto de autores para argumentar que as organizações, ao implementarem seus processos decisórios específicos, devem considerar quatro modelos: a) Modelo Racional, que identifica o problema e suas variáveis associadas, busca e/ou cria soluções e seleciona a mais conveniente; b) Modelo Processual, baseado na estruturação da decisão em torno de fases e ciclos de atividades num fluxo de ação previamente determinado; c) Modelo Político, no qual a decisão deve ser fruto de negociação; e d) Modelo Anárquico, aplicável a processos decisórios desorganizados ou complexos.

A tomada de decisões também possui recursos interdependentes essenciais para o seu funcionamento: as preferências quanto à avaliação e escolha de soluções (as quais são do tipo emocional, fundadas na cultura da organização), as rotinas de decisão usadas na prática (tipo ativo/situacional)e as regras formais que estabelecem os comportamentos e a participação de cada um nos processos decisórios (tipo cognitivo). 


\subsection{O que é uma organização do conhecimento para Choo?}

Para o autor, tornam-se organizações do conhecimento aquelas que alcançam elevados patamares de integração dos três usos estratégicos da informação. Nessa condição, estabelecese um ciclo initerrupto de aprendizagem e adaptação chamado "ciclo do conhecimento" (Figura 2), no qual os três usos se complementam e se alimentam mutuamente (CHOO, 2006). Note o destaque dado pela figura aos recursos organizacionais interdependentes, essenciais para o funcionamento de cada um dos usos estratégicos da informação.

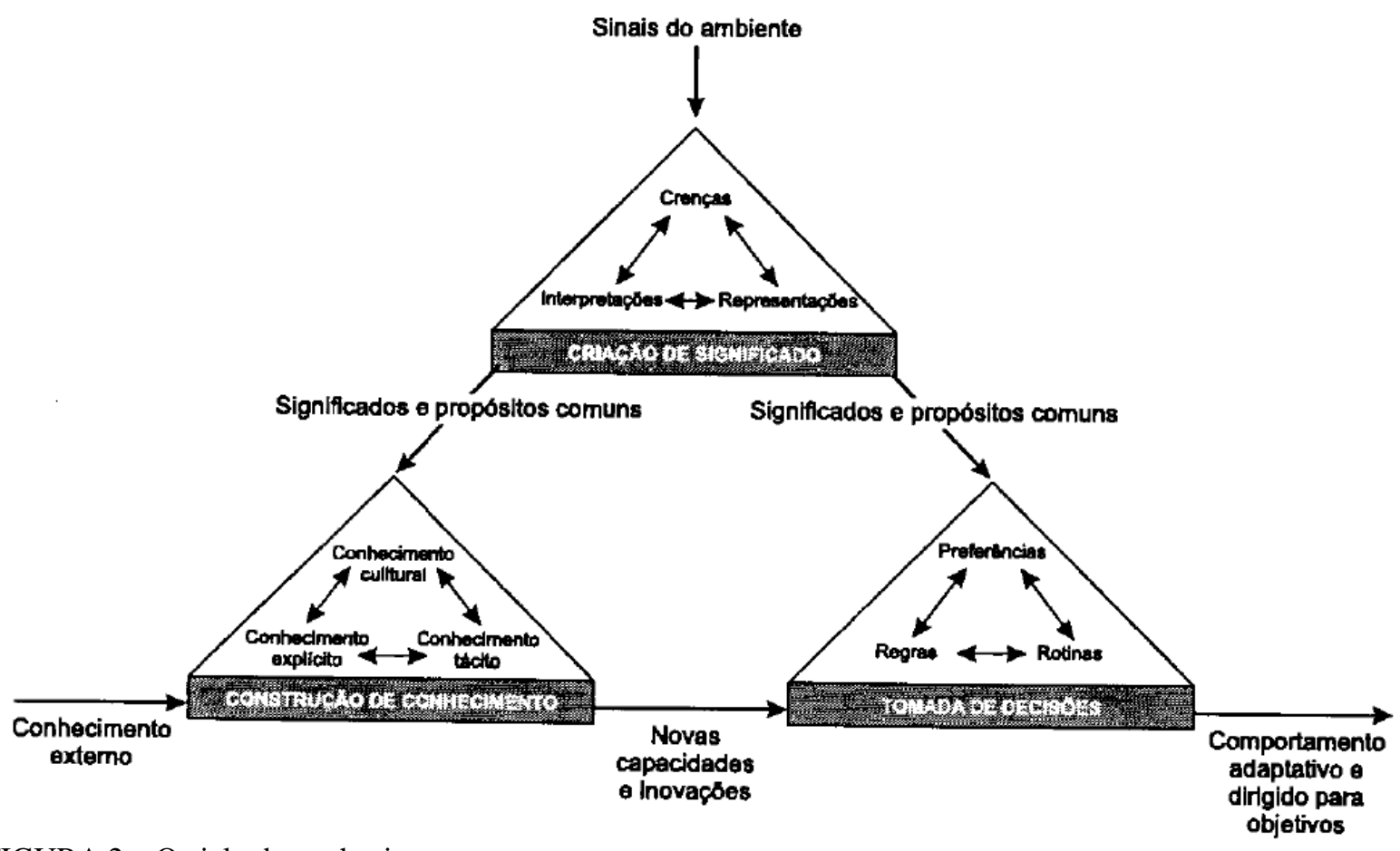

FIGURA 2 - O ciclo do conhecimento

Fonte: Choo (2006, p. 377)

As setas que unem os usos na figura mostram o primeiro nível de integração. Percebese que os mesmos se sustentam mutuamente, de modo que a ausência ou falha de qualquer um inviabiliza o sistema como um todo. Já o segundo nível (não explícito na Figura 2) é composto por três tríades, cada qual unindo recursos dos três usos que comungam da mesma natureza. As tríades representam, na verdade, um princípio de coerência interna: apesar de comporem usos diferentes, recursos de mesma natureza precisam se conectar e reforçarem-se mutuamente para que haja coesão sistêmica.

Choo associa as tríades aos recursos cognitivos, emocionais e ativos/situacionais utilizados pelos três usos da informação. Para ele, a administração desses recursos, 
O modelo de excelência da gestão (MEG) favorece a existência das organizações do conhecimento de Chun W. Choo?

considerando sua similaridade, representa um dos sustentáculos do modelo. As tríades são as seguintes:

- Tríade da Cultura Organizacional: formada pelos recursos emocionais, que correspondem aos elementos da cultura pertencentes aos três usos (as crenças na criação de significado, o conhecimento cultural na construção de conhecimento e as preferências na tomada de decisões).

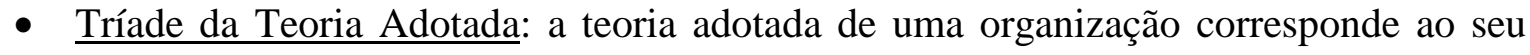
modelo formal de gestão, composto por políticas, práticas documentadas, organograma, etc. Alguns desses elementos compõem os recursos cognitivos dos três usos da informação: as interpretações (criação de significado), o conhecimento explícito (construção de conhecimento) e as regras (tomada de decisões).

- $\quad$ Tríade da Teoria em Uso: a teoria em uso diz respeito às práticas e comportamentos organizacionais reais, nem sempre condizentes com a teoria adotada. As representações (criação de significado), o conhecimento tácito (construção de conhecimento) e as rotinas (tomada de decisões) são recursos ativos/situacionais e elementos da teoria em uso, presentes nos três usos estratégicos da informação.

\section{O MEG favorece a existência das organizações do conhecimento?}

Responder a essa pergunta equivale a indicar se uma organização que utiliza o MEG plenamente possui (ou não) vantagens para se tornar uma organização do conhecimento.

Tomar o uso pleno do MEG como referência foi necessário porque ele é um modelo evolutivo e, como tal, só manifesta a real natureza de seus elementos primordiais (i.e., os fundamentos da excelência, os critérios do modelo e seus itens constituintes, os fatores de avaliação e outros elementos - como os ciclos PDCA/PDCL) na condição de uso pleno (i.e., no estágio de excelência). Sendo assim, para sabermos se a essência do MEG favorece a existência das organizações do conhecimento, foi necessário adotar essa estratégia.

Sob essas condições, para que a resposta à pergunta seja verdadeira, é preciso que:

- Não haja conflito entre os elementos primordiais do MEG e as condições necessárias e suficientes para a existência da organização do conhecimento; e 
- A manifestação dos elementos primordiais do MEG favoreça ao menos uma parte das condições necessárias e suficientes para a existência da organização do conhecimento.

A estratégia para a verificação desses tópicos está representada na Figura 3. A título de referência, as condições necessárias e suficientes para a existência da organização do conhecimento, indicadas na seção 4 , são as seguintes:

- Existência dos três usos estratégicos da informação (Criação de Significado, Construção do Conhecimento e Tomada de Decisão);

- Integração dos três usos por meio da troca de informações entre eles (vide as setas entre os usos, mostradas na Figura 2);

- Integração dos três usos por meio das tríades da Cultura Organizacional, da Teoria Adotada e da Teoria em Uso (vide subseção 4.4).

Condicões necessárias e suficientes para a existência da organização do conhecimento de CHOO

A existência dos três usos estratégicos da informação: Criação de Significado (CS), Construção do Conhecimento (CC) e Tomada de Decisão (TD)

Integração dos três usos por meio da troca de informações entre eles (i.e., trocas entre CS e CC, trocas entre CS e TD e trocas entre CC e TD)

Integração dos três usos por meio das tríades da Cultura Organizacional, da Teoria Adotada e da Teoria em Uso

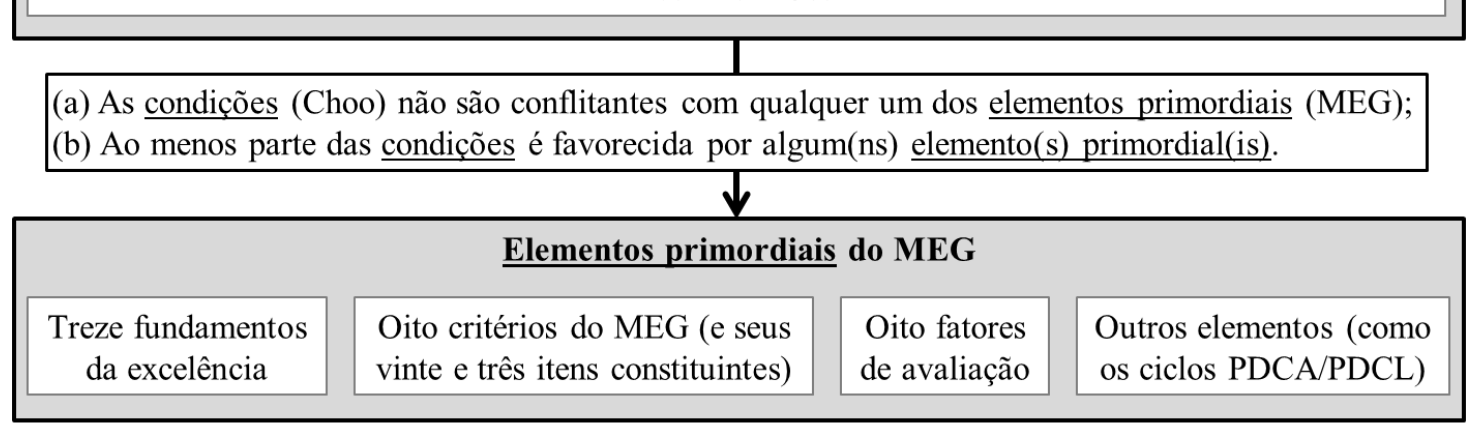

Se (a) e (b) forem verdadeiros, então o MEG favorece as organizações do conhecimento!

FIGURA 3 - Estratégia para verificação da resposta à pergunta-título do artigo

Fonte: Elaborada pelo autor. 


\subsection{O MEG favorece os três usos estratégicos da informação?}

Nessa subseção, discute-se a relação entre o MEG e a primeira das três condições de Choo para a existência da organização do conhecimento (i.e., a presença dos três usos estratégicos da informação). Para essa condição em particular, realizou-se duas análises:

- Uma baseada nos processos específicos citados por Choo: Como apontado na seção 4, Choo indica processos específicos para a implementação de cada um dos três usos estratégicos da informação (por exemplo, o Sensemaking de Karl E. Weick para a criação de significado). Sendo assim, uma das formas do MEG favorecer os usos seria absorvendo os processos específicos citados por Choo. Com isso, eles passariam a gozar de todas as vantagens políticas, orçamentárias e de pessoal conferidas ao MEG, o que lhes seria muito positivo. No entanto, para que essa absorção seja possível, é preciso que esses processos satisfaçam ao menos um item de algum critério do MEG. Sendo assim, resultou dessa análise uma lista dos itens do MEG passíveis de serem satisfeitos pelos processos indicados por Choo.

- Outra focada na lógica e na finalidade dos três usos da informação, independente de processos/autores específicos: Não parece crível que os processos específicos citados por Choo sejam os únicos capazes de implementar os usos estratégicos da informação. Sendo assim, procedeu-se a uma análise mais conceitual da essência dos três usos frente aos elementos do MEG, da qual resultou um posicionamento mais abrangente quanto à relação entre os modelos.

Para facilitar essas análises, cada um dos três usos foi tratado separadamente. No entanto, há dois temas que dizem respeito aos três e que, por isso, serão discutidos na sequencia. O primeiro é a gestão da informação.

A Figura 4 apresenta a perspectiva de Choo para essa atividade. Para o autor, é no âmbito dessa rede de processos que se dá o real uso da informação (incluindo aí os três usos estratégicos). Já o MEG trata da gestão da informação em seu critério "Informações e Conhecimento", por meio do item "Informações da organização". 


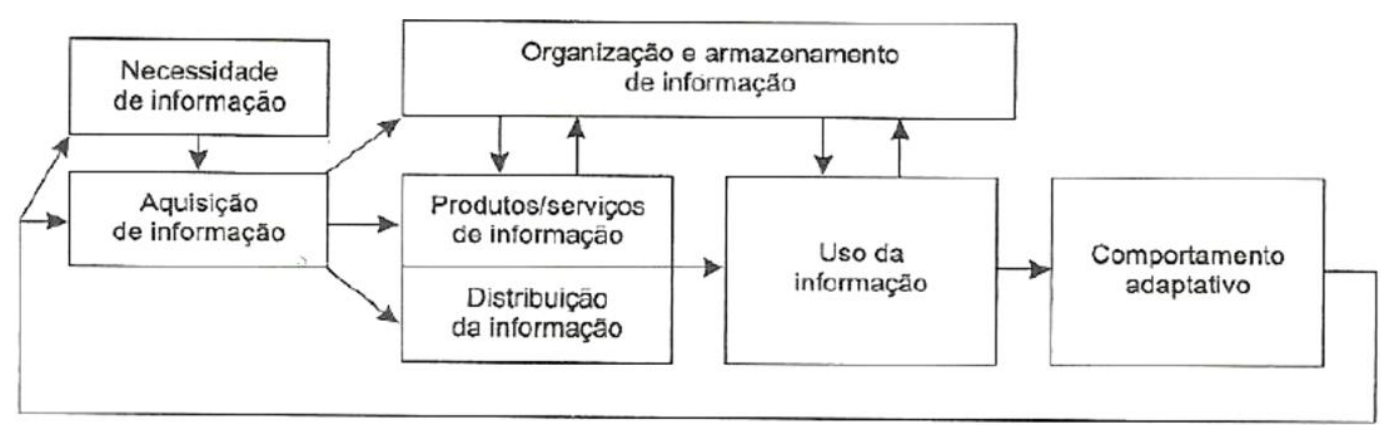

FIGURA 4 - Modelo processual de gestão da informação

Fonte: Choo (2006, p. 404).

Os dois modelos possuem muitas semelhanças no que diz respeito a esse tema, apesar de algumas diferenças, ocorridas em função da forte valorização dos sistemas de informação computadorizados no MEG, em contraste com o destaque dado por Choo aos aspectos mais humanos do ciclo da informação. No entanto, a convergência entre as abordagens e a importância dada pelos modelos a esse tema comum já apontam a centralidade do critério "Informações e Conhecimento" no favorecimento do modelo de Choo pelo MEG.

O segundo tema que impacta os três usos é o da relação entre o MEG e a dinâmica homeostase x adaptabilidade. No início dessa seção, viu-se que os três usos da informação dependem das tensões entre o novo e o velho. Nesse sentido, o MEG favoreceria mais o surgimento das organizações do conhecimento se o mesmo, bem como seus elementos primordiais, suportasse esse tipo de tensão.

Por se basear numa visão sistêmica da gestão o MEG, por concepção, compreende as organizações como sistemas abertos, dependentes do ambiente. Desse modo, a busca da conciliação entre a homeostase e a adaptabilidade é imprescindível para o modelo, o que reflete em seus elementos constituintes:

- No que diz respeito aos fundamentos da excelência, a "Agilidade", o "Olhar para o futuro" e principalmente o "Pensamento sistêmico" alinham-se fortemente ao reconhecimento e à exploração dessa tensão. Dois outros fundamentos ("Aprendizado organizacional" e "Inovação") representam eles mesmos pólos opostos, de natureza muito similar àquela associada por Choo aos itens "Exploração" e "Investigação" (vide a subseção 4.2, dedicada à construção de conhecimento);

- Quanto aos critérios e seus itens, o confronto entre o novo e velho é a regra. A onipresença dos ciclos PDCA/PDCL garante essa dinâmica a cada prática gerencial da organização. Além disso, alguns itens específicos (como a "Formulação de estratégias" 
O modelo de excelência da gestão (MEG) favorece a existência das organizações do conhecimento de Chun W. Choo?

e o "Conhecimento da organização") fundamentam-se nesse confronto para existir assim como os usos estratégicos da informação;

- Por fim, os fatores de avaliação "Enfoque", "Aprendizado" e "Melhoria" relacionam-se diretamente a esse contexto, na medida em que avaliam aspectos das práticas e dos resultados organizacionais dependentes tanto da mudança quanto da harmonia.

Resulta disso que o MEG favorece a necessidade, expressa pelo modelo de Choo, de reconhecer e harmonizar tensões por meio do uso estratégico da informação.

\section{i. OMEG favorece a criação de significado?}

Como visto na seção 3, os fundamentos da excelência são o alicerce do MEG. A busca por implementar tais princípios é, portanto, central. Uma vez que dois desses fundamentos ("Conhecimento sobre clientes e mercado" e principalmente "Olhar para o futuro") estão atrelados à criação de significado, a implementação de ambos favorece esse uso estratégico da informação. Além disso, devido à natureza sistêmica do MEG, vários critérios e seus itens associam-se à compreensão do ambiente (vide Quadro 4).

Como visto anteriormente, Choo indica o Sensemaking como o processo para implementação da criação de significado. Suas características e resultados podem ser vinculados a diferentes itens dos critérios MEG, como também mostra o quadro abaixo. 
QUADRO 4 - O MEG favorecendo a criação de significado

\begin{tabular}{|c|c|}
\hline $\begin{array}{l}\text { Fundamentos } \\
\text { da excelência }\end{array}$ & $\begin{array}{l}\text { Os fundamentos "Olhar para o futuro" e "Conhecimento sobre clientes e mercados" tratam } \\
\text { da compreensão do ambiente externo à organização, tendo portanto o mesmo objeto e } \\
\text { objetivo da criação de significado. O fundamento "Agilidade" também é importante, já que } \\
\text { incute na organização o princípio da atenção proativa às novas demandas de clientes e do } \\
\text { mercado, o que naturalmente implica a compreensão de aspectos essenciais do ambiente } \\
\text { externo. }\end{array}$ \\
\hline Critérios & $\begin{array}{l}\text { Como o fundamento "Olhar para o futuro" baliza o critério "Estratégias e Planos", e o } \\
\text { fundamento "Conhecimento sobre clientes e mercados" é referência para o critério } \\
\text { "Clientes", alguns de seus itens estão alinhados à análise e compreensão do ambiente } \\
\text { externo. Também o critério "Liderança", por sua estreita vinculação à "Estratégias e } \\
\text { Planos" e por sua atribuição de fomentar a construção e divulgação de consensos sob os } \\
\text { quais se baseiam as açôes coletivas, e o critério "Sociedade", por lidar com diversos } \\
\text { elementos presentes no ambiente externo, também envolvem práticas que contribuem para } \\
\text { a criação de significado. Por fim, o critério "Informações e conhecimento" também } \\
\text { contribui para a criação de significado, por meio de seus dois itens. }\end{array}$ \\
\hline \multirow{8}{*}{$\begin{array}{l}\text { Itens que } \\
\text { favorecem o } \\
\text { Sensemaking }\end{array}$} & Cultura organizacional e desenvolvimento da gestão: devido à sua vinculação às crenças, o \\
\hline & $\begin{array}{l}\text { Sensemaking pode funcionar como processo gerencial de identificação, análise e } \\
\text { desenvolvimento de elementos da cultura organizacional. }\end{array}$ \\
\hline & $\begin{array}{l}\text { Análise do desempenho da organização: o Sensemaking pode contribuir na identificação de } \\
\text { referenciais comparativos e no estabelecimento do panorama externo, ambos necessários à } \\
\text { análise do desempenho da organização. }\end{array}$ \\
\hline & $\begin{array}{l}\text { Formulação das estratégias: o Sensemaking viabiliza a análise externa (macroambiente, } \\
\text { setor e mercados de atuação), essencial na formulação de estratégias. }\end{array}$ \\
\hline & $\begin{array}{l}\text { Análise e desenvolvimento de mercado: o Sensemaking é capaz de apoiar diferentes } \\
\text { aspectos da análise dos mercados atual e potencial das organizações, incluindo a percepção } \\
\text { das mudanças de comportamento de clientes, o surgimento de tendências, o monitoramento } \\
\text { de novidades nas marcas concorrentes, etc. }\end{array}$ \\
\hline & $\begin{array}{l}\text { Desenvolvimento social: o Sensemaking permite que a organização perceba mudanças nas } \\
\text { necessidades/expectativas da sociedade e quanto ao desenvolvimento social. }\end{array}$ \\
\hline & $\begin{array}{l}\text { Informações da organização: o Sensemaking apóia a satisfação das necessidades } \\
\text { informacionais da organização por meio das interpretações ambientais que gera. }\end{array}$ \\
\hline & $\begin{array}{l}\text { Conhecimento da organização: o Sensemaking contribui para a identificação de novos } \\
\text { conhecimentos e tecnologias importantes para a organização. }\end{array}$ \\
\hline
\end{tabular}

Fonte: FUNDAÇÃO NACIONAL DA QUALIDADE, 2011b; 2011c; 2011d; 2011f; 2013. 
O modelo de excelência da gestão (MEG) favorece a existência das organizações do conhecimento de Chun W. Choo?

\section{ii. $\quad$ O MEG favorece a construção de conhecimento?}

Para o MEG, a competitividade das organizações é pautada pelo aprendizado contínuo e pela inovação, havendo portanto grande vinculação entre o modelo e a construção de conhecimento. Esses vínculos estão indicados no Quadro 5, que também apresenta os itens do MEG mais similares ao processo de conversão do conhecimento de Nonaka e Takeuchi (selecionado dentre os três processos indicados por Choo para a implementação da construção de conhecimento por ser o mais conhecido).

QUADRO 5 - O MEG favorecendo a construção de conhecimento

\begin{tabular}{|c|c|}
\hline $\begin{array}{l}\text { Fundamentos } \\
\text { da excelência }\end{array}$ & $\begin{array}{l}\text { Os fundamentos "Inovação", "Aprendizado organizacional" e "Valorização das pessoas e } \\
\text { da cultura" preconizam a geração de novos conhecimentos, expertises e inovações em } \\
\text { produtos e processos, correspondendo perfeitamente à construção de conhecimento de } \\
\text { Choo }\end{array}$ \\
\hline Critérios & $\begin{array}{l}\text { A "Inovação" e o "Aprendizado organizacional" balizam o critério "Liderança", } \\
\text { direcionando-o à busca da competitividade por meio da valorização dos recursos humanos } \\
\text { e da inovação permanente. Já a "Valorização das pessoas e da cultura", que preconiza as } \\
\text { ações de treinamento e desenvolvimento voltadas à ampliação da expertise alinhada aos } \\
\text { objetivos estratégicos da organização, vincula-se ao critério "Pessoas". O critério } \\
\text { "Informações e conhecimento" é essencial, já que contém o item mais relacionado à } \\
\text { criação de conhecimento: "Conhecimento da organização". O critério "Estratégias e } \\
\text { planos" é estruturante nesse contexto: por meio de suas práticas, esse critério aponta os } \\
\text { rumos, além de garantir o aporte de recursos para o desenvolvimento de expertise, de } \\
\text { inovações e de melhorias ao longo do tempo. }\end{array}$ \\
\hline \multirow{4}{*}{$\begin{array}{c}\text { Itens que } \\
\text { favorecem o } \\
\text { processo de } \\
\text { Conversão do } \\
\text { Conhecimento } \\
\text { de Nonaka e } \\
\text { Takeuchi }\end{array}$} & Conhecimento da organização: a abordagem de Nonaka e Takeuc \\
\hline & $\begin{array}{l}\text { Informações da organização: todas as etapas de conversão de conhecimento explícito de } \\
\text { Nonaka e Takeuchi valem-se do sistema de informação da organização, cujo } \\
\text { funcionamento inscreve-se nesse item. }\end{array}$ \\
\hline & $\begin{array}{l}\text { Formulação das estratégias: o processo de Nonaka e Takeuchi contempla uma parte } \\
\text { fundamental desse item, relativa à identificação, desenvolvimento e avaliação dos ativos } \\
\text { intangíveis estratégicos da organização. }\end{array}$ \\
\hline & $\begin{array}{l}\text { Processos da cadeia de valor: no âmbito desse item, avalia-se tanto o potencial das ideias } \\
\text { passíveis de serem convertidas em inovações, quanto a viabilidade e as formas de } \\
\text { incorporação de novas tecnologias no desenvolvimento e melhoria de produtos e } \\
\text { processos. Essa função é perfeitamente ajustável ao processo de Nonaka e Takeuchi. }\end{array}$ \\
\hline $\begin{array}{l}\text { Fatores de } \\
\text { avaliação }\end{array}$ & $\begin{array}{l}\text { O fator de avaliação "Aprendizado" vincula-se fortemente à construção de conhecimento, } \\
\text { uma vez que estimula processos sistemáticos e initerruptos de busca de melhorias, de } \\
\text { inovações e de conhecimentos essenciais à competitividade. }\end{array}$ \\
\hline
\end{tabular}

Fonte: FUNDAÇÃO NACIONAL DA QUALIDADE, 2011b; 2011f; 2011g; 2013. 


\section{iii. $\quad$ OMEG favorece a tomada de decisões?}

A tomada de decisões é valorizada em toda a documentação do MEG, mas aparece com mais destaque em alguns fundamentos e critérios (vide Quadro 6). Dada a relação entre decisão e avaliação, considera-se que todos os fatores de avaliação vinculam-se a esse uso estratégico da informação.

Quanto à análise dos processos específicos, Choo indica quatro modelos decisórios diferentes, aplicáveis em diferentes condições e contextos. Diante disso, não faria sentido buscar uma vinculação entre os itens do MEG e os modelos. Optou-se, então, pela busca dos itens mais intrinsecamente vinculados à tomada de decisão, que também aparecem no quadro.

QUADRO 6 - O MEG favorecendo a tomada de decisões

\begin{tabular}{|c|c|}
\hline & $\begin{array}{l}\text { O fundamento "Decisões fundamentadas" preconiza que as decisões na organização devem } \\
\text { ser tomadas com base nas melhores informações e análises de risco disponíveis, colocando } \\
\text { em destaque o processo qualificado de tomada de decisão. Da mesma forma, o fundamento } \\
\text { "Orientações por processos" fomenta decisões para a busca contínua da eficiência e da } \\
\text { eficácia nos processos organizacionais. Já a "Agilidade" diz respeito à flexibilidade e à } \\
\text { rapidez de adaptação às demandas de clientes e do mercado, o que implica um processo } \\
\text { dinâmico de decisão. }\end{array}$ \\
\hline & $\begin{array}{l}\text { A tomada de decisão permeia todos os critérios gerenciais, uma vez que o binômio decisão- } \\
\text { ação representa a essência da gestão. Em especial, o critério "Liderança" destaca o modo } \\
\text { estruturado e sistemático com que as principais decisões da organização são tomadas, } \\
\text { comunicadas e conduzidas, respeitando valores, princípios e os direitos das partes } \\
\text { interessadas. O critério "Informações e conhecimento" também destaca a importância da } \\
\text { tomada de decisão, trazendo em todos os seus itens a preocupação de municiar os decisores } \\
\text { nos diversos níveis hierárquicos com informações pertinentes às suas decisões. Em } \\
\text { "Estratégias e planos", ve-se a presença marcante da tomada de decisão, seja definindo os } \\
\text { rumos da organização ou acompanhando o cumprimento da estratégia. }\end{array}$ \\
\hline $\begin{array}{l}\text { Itens mais } \\
\text { vinculados à } \\
\text { tomada de } \\
\text { decisão }\end{array}$ & $\begin{array}{l}\text { Governança: um dos elementos desse item trata especificamente do modo como os } \\
\text { processos decisórios são realizados e as decisões são comunicadas e implementadas. } \\
\text { Análise do desempenho da organização: esse item prevê um conjunto de decisões, } \\
\text { decorrentes da análise de desempenho organizacional. } \\
\text { Formulação das estratégias: as decisões estratégicas quanto ao futuro da organização } \\
\text { relacionam-se a esse item. } \\
\text { Informações da organização: todos os elementos desse item dizem respeito à satisfação das } \\
\text { necessidades informacionais das pessoas, de modo a apoiar suas decisões e ações. Sendo } \\
\text { assim, todos os processos decisórios têm algum tipo de vinculação com esse item. } \\
\text { Processos da cadeia de valor: aqui, a avaliação do potencial das novas ideias e tecnologias } \\
\text { resulta em decisões sobre o desenvolvimento de produtos e processos. }\end{array}$ \\
\hline & $\begin{array}{l}\text { derarmos que toda avaliação serve para balizar uma decisão, todos os fatores de } \\
\text { contribuem para a tomada de decisão. }\end{array}$ \\
\hline & D. \\
\hline
\end{tabular}

Fonte: FUNDAÇÃO NACIONAL DA QUALIDADE, 2011b; 2011c; 2011d; 2011e; 2011f; 2011g; 2011h; 2011i; 2013.

InCID: R. Ci. Inf. e Doc., Ribeirão Preto, v. 7, n. 1, p. 66-89, mar./ago. 2016. 
O modelo de excelência da gestão (MEG) favorece a existência das organizações do conhecimento de Chun W. Choo?

A análise da documentação do MEG não indicou qualquer conflito entre seus elementos e os três usos estratégicos da informação de Choo. Ao contrário, vários elementos favoráveis tanto à lógica/finalidade dos três usos quanto aos processos específicos indicados por Choo foram encontrados. Sendo assim, considera-se que o MEG favorece os três usos estratégicos da informação.

\subsection{O MEG favorece a integração dos três usos estratégicos da informação por meio de troca de informações?}

A análise dessa questão foi dividida em duas partes: na primeira, buscou-se elementos do MEG que favorecessem a integração simultânea dos três usos da informação; já a segunda se concentrou nos elementos que promoviam a integração dos usos dois a dois.

No que diz respeito à integração simultânea dos três usos, além do item "Informações da organização", responsável pela gestão da informação, o Quadro 7 apresenta outros elementos do MEG que favorecem essa situação. Há dois mecanismos sistêmicos do MEG que naturalmente fomentam trocas de informações entre os processos integrantes do modelo: o fundamento "Pensamento sistêmico" e o fator de avaliação "Integração". Além disso, a vinculação dos três usos aos critérios "Liderança", "Estratégias e Planos" e "Informações e Conhecimento" também promove a troca de informações entre eles.

QUADRO 7 - Elementos do MEG que favorecem a troca de informações entre os três usos

\begin{tabular}{|c|c|}
\hline & $\begin{array}{l}\text { O fundamento "Pensamento sistêmico" provoca continuamente a organização a } \\
\text { compreender as relações de interdependência entre seus componentes e práticas, criando } \\
\text { um ambiente propício à integração. }\end{array}$ \\
\hline & $\begin{array}{l}\text { O critério "Estratégias e Planos", em seu item "Formulação das estratégias", preconiza a } \\
\text { análise externa (vinculada à criação de significado) aliada à análise interna (que inclui e } \\
\text { destaca o capital intelectual da organização, responsável por seus diferenciais } \\
\text { competitivos). Esse é um dos mais importantes contextos para a troca de informações entre } \\
\text { os três usos estratégicos da informação e seus processos. Já o critério "Liderança", por sua } \\
\text { ligação à "Estratégias e Planos" e sua atribuição de fomentar a construção e divulgação de } \\
\text { consensos sob os quais se baseiam as ações coletivas (inclusive as de inovação), também } \\
\text { desempenha um papel indispensável na integração dos usos. Por fim, o critério } \\
\text { "Informações e conhecimento" contribui com os três usos da informação por meio da } \\
\text { gestão da informação, vinculada ao item "Informações da organização", gerando o contexto } \\
\text { mais essencial para a integração. }\end{array}$ \\
\hline & $\begin{array}{l}\text { O fator de avaliação "Integração" avalia a interligação das prát } \\
\text { como um instrumento de incentivo da aplicação do "Pensamen } \\
\text { como um todo, favorecendo assim a integração. }\end{array}$ \\
\hline
\end{tabular}

Fonte: FUNDAÇÃO NACIONAL DA QUALIDADE, 2011b; 2011c; 2011f; 2013.

InCID: R. Ci. Inf. e Doc., Ribeirão Preto, v. 7, n. 1, p. 66-89, mar./ago. 2016. 
Os tópicos abaixo dedicam-se à análise da integração entre os usos, dois a dois. Para a descoberta desses vínculos, analisou-se os resultados da subseção 5.1 em busca de itens do MEG compartilhados apenas pelos pares de usos da informação.

\section{iv. Relação criação de significado - construção de conhecimento por meio do MEG}

A subseção 5.1 mostra que um item do MEG, compartilhado exclusivamente pela criação de significado e pela construção de conhecimento: o "Conhecimento da organização". Isso significa que os processos de Sensemaking e de Conversão do Conhecimento de Nonaka e Takeuchi tendem a cooperar por intermédio desse item, facilitando a troca de informações.

\section{v. $\quad$ Relação criação de significado - tomada de decisões por meio do MEG:}

Os elementos primordiais do MEG compartilhados exclusivamente pela criação de significado e pela tomada de decisões são os seguintes: o fundamento "Agilidade", o critério "Clientes e Sociedade" e o item "Análise do desempenho da organização". Aqui, percebe-se uma maior gama de oportunidades de integração que no item anterior.

\section{vi. $\quad$ Relação construção de conhecimento - tomada de decisões por meio do MEG:}

Os elementos do MEG compartilhados apenas pela construção de conhecimento e pela tomada de decisões são os seguintes: o critério "Pessoas", o item "Processos da cadeia de valor" e o fator de avaliação "Aprendizado".

Considerando os argumentos apresentados, pode-se concluir que o MEG favorece a integração dos três usos por meio da troca de informações entre eles. 
O modelo de excelência da gestão (MEG) favorece a existência das organizações do conhecimento de Chun W. Choo?

\subsection{O MEG favorece a integração dos três usos estratégicos da informação por meio das as tríades da Cultura Organizacional, da Teoria Adotada e da Teoria em Uso?}

Como as tríades dependem, na prática, de uma gestão da informação adequada, serão os esforços gerenciais no âmbito do item "Informações da organização" que garantirão a sua existência. Esse apoio do MEG torna-se, portanto, decisivo para a realização dessa terceira condição para a existência das organizações do conhecimento.

Por outro lado, como a documentação do MEG trata apenas dos recursos cognitivos, configura-se aí uma lacuna importante no que diz respeito às tríades. Essa constatação reforça a necessidade da ação consciente de profissionais da informação, conhecedores do modelo de Choo, na ampliação do escopo original da gestão da informação preconizada pelo MEG no sentido de incorporar os recursos emocionais e ativos/situacionais necessários.

Essa incorporação não nos parece exdrúxula, haja vista os indícios apontando o MEG como facilitador das tríades. Os fatores de avaliação do modelo e os ciclos PDCA/PDCL fomentam uma vinculação intensa entre as teorias adotada e em uso. Disso decorre um contexto favorável aos vínculos entre os elementos das duas teorias, facilitando o surgimento das tríades. Se somarmos a isso o potencial de integração dos três usos da informação discutidos anteriormente, nota-se o terreno fértil para as tríades criado pelo MEG.

\section{Considerações finais}

O presente trabalho discute se o pleno uso do Modelo de Excelência da Gestão (MEG) favorece a existência das organizações do conhecimento de Choo. A partir da análise da documentação sobre o MEG, o artigo apresenta um conjunto de indícios tanto do favorecimento dos três usos estratégicos da informação, quanto da integração entre eles. Sendo essas as condições necessárias e suficientes para a existência da organização do conhecimento de Choo, considera-se que o MEG favorece a sua existência.

Esse entendimento é convergente tanto com a contribuição de Obregon, Dziekaniak e Vanzin (2012), que relaciona o MEG à gestão do conhecimento, quanto com a descoberta de Duarte, Silva e Costa (2007) de que organizações bem avaliadas pelos programas estaduais da qualidade (vinculados à FNQ e baseados no MEG) desenvolvem práticas de gestão da informação e do conhecimento condizentes com a literatura. 
No entanto, o artigo também revela discrepâncias entre os modelos. Por exemplo, para Choo o conhecimento organizacional é uma propriedade emergente da dinâmica social, que resulta da relação entre os três processo de uso estratégico da informação. Por outro lado, uma análise da documentação do critério "Informações e conhecimento" revela implicitamente a visão do "conhecimento como coisa". Sendo essa a perspectiva dominante no âmbito das organizações, essa realidade não chega a surpreender, porém impõe limitações ao pleno funcionamento do ciclo do conhecimento.

Essa e as demais discrepâncias percebidas podem ser superadas pela intervenção de profissionais da informação conhecedores do modelo de Choo, com influência e motivação suficientes para atuar sobretudo no âmbito da gestão da informação. Se assim o for, tanto as lacunas quanto os pontos essenciais para a existência e a integração dos três usos da informação poderão ser tratados adequadamente.

Sabe-se que a literatura sobre informação e conhecimento nas organizações está repleta de boas ideias, mas que muitas nunca são implementadas devido às incompatibilidades com a cultura e/ou com o modelo de gestão vigente. Esse artigo procurou mostrar que, no que diz respeito ao MEG e o modelo de organização do conhecimento de Choo, esse não é o caso. A elucidação da mútua compatibilidade, bem como das oportunidades passíveis de serem exploradas durante os esforços de integração, poderá favorecer o surgimento de novas organizações do conhecimento, bem como ampliar o sucesso das organizações e de seus profissionais da informação. 
O modelo de excelência da gestão (MEG) favorece a existência das organizações do conhecimento de Chun W. Choo?

\section{Referências}

CHOO, C. W. A organização do conhecimento: como as organizações usam a informação para criar conhecimento, construir conhecimento e tomar decisões. 2. ed. São Paulo: Senac, 2006.

DUARTE, E. N.; SILVA, A. K. A.; COSTA, S. Q. Gestão da informação e do conhecimento: práticas de empresa "excelente em gestão empresarial" extensivas às unidades de informação. Informação e Sociedade: Estudos, v. 17, n. 1, p. 97-107, jan./abr., 2007.

FERREIRA, A. R. Modelo de excelência em gestão pública. Revista Eixo, n. 1, v. 1, p. 3143, jan./jun., 2012.

FUNDAÇÃO NACIONAL DA QUALIDADE (FNQ). Cadernos de excelência: introdução ao modelo de excelência da gestão. 4. ed. rev. e ampl. São Paulo: FNQ, 2011a. 27 p. (Série Cadernos de Excelência, 1) de Excelência, 2) : liderança. 4. ed. rev. e ampl. São Paulo: FNQ, 2011b. 51 p. (Série Cadernos : estratégias e planos. 4. ed. rev. e ampl. São Paulo: FNQ, 2011c. 39 p. (Série Cadernos de Excelência, 3) de Excelência, 4) : clientes. 4. ed. rev. e ampl. São Paulo: FNQ, 2011d. 27 p. (Série Cadernos de Excelência, 5)

: sociedade. 4. ed. rev. e ampl. São Paulo: FNQ, 2011e. 27 p. (Série Cadernos : informações e conhecimento. 4. ed. rev. e ampl. São Paulo: FNQ, 2011f. 31 p. (Série Cadernos de Excelência, 6) de Excelência, 7) : pessoas. 4. ed. rev. e ampl. São Paulo: FNQ, 2011 g. 43 p. (Série Cadernos de Excelência, 8)

: processos. 4. ed. rev. e ampl. São Paulo: FNQ, 2011 h. 47 p. (Série Cadernos de Excelência, 9)

: resultados. 4. ed. rev. e ampl. São Paulo: FNQ, 2011i. 39 p. (Série Cadernos : guia de autoavaliação e implementação de melhorias. 4. ed. rev. e ampl. São Paulo: FNQ, 2011j. 47 p. (Série Cadernos de Excelência, 10)

Critérios de excelência. 20. ed., São Paulo: FNQ, 2013. 128 p.

NONAKA, I.; TAKEUCHI, H. Criação do conhecimento na empresa. Rio de Janeiro: Campus, 1997. 
OBREGON, R. F. A.; DZIEKANIAK, G. V.; VANZIN, T. A emergência da gestão do conhecimento para ancorar a excelência organizacional. Perspectivas em Gestão \& Conhecimento, v. 2, n. 1, p. 218-227, jan./jun., 2012.

PAGLIUSO, A. T.; CARDOSO, R.; SPIEGEL, T. Gestão organizacional: o desafio da construção de modelo de gestão. São Paulo: Saraiva, 2010. 155 p.

Artigo submetido em: 03 ago. 2015

Artigo aceito em: 23 out. 2015 